\title{
K143R Amino Acid Substitution in 14- $\alpha$-Demethylase (Erg11p) Changes Plasma Membrane and Cell Wall Structure of Candida albicans
}

\author{
Daria Derkacz $^{1}(\mathbb{D})$, Przemysław Bernat ${ }^{2}(\mathbb{D})$ and Anna Krasowska ${ }^{1, *(\mathbb{D})}$ \\ 1 Department of Biotransformation, Faculty of Biotechnology, University of Wroclaw, 50-383 Wroclaw, Poland; \\ daria.derkacz@uwr.edu.pl \\ 2 Department of Industrial Microbiology and Biotechnology, Faculty of Biology and Environmental Protection, \\ University of Łódź, 90-237 Lodz, Poland; przemyslaw.bernat@biol.uni.lodz.pl \\ * Correspondence: anna.krasowska@uwr.edu.pl;
}

check for

updates

Citation: Derkacz, D.; Bernat, P.;

Krasowska, A. K143R Amino Acid Substitution in 14- $\alpha$-Demethylase (Erg11p) Changes Plasma Membrane and Cell Wall Structure of Candida albicans. Int. J. Mol. Sci. 2022, 23, 1631. https://doi.org/10.3390/ijms23031631

Academic Editors: Costantini

Claudio, Giorgia Renga and

Vasileios Oikonomou

Received: 30 December 2021

Accepted: 28 January 2022

Published: 31 January 2022

Publisher's Note: MDPI stays neutral with regard to jurisdictional claims in published maps and institutional affiliations.

Copyright: () 2022 by the authors. Licensee MDPI, Basel, Switzerland. This article is an open access article distributed under the terms and conditions of the Creative Commons Attribution (CC BY) license (https:// creativecommons.org/licenses/by/ $4.0 /)$.

\begin{abstract}
The opportunistic pathogen Candida albicans is responsible for life-threating infections in immunocompromised individuals. Azoles and polyenes are two of the most commonly used antifungals and target the ergosterol biosynthesis pathway or ergosterol itself. A limited number of clinically employed antifungals correspond to the development of resistance mechanisms. One resistance mechanism observed in clinical isolates of azole-resistant $C$. albicans is the introduction of point mutations in the ERG11 gene, which encodes a key enzyme (lanosterol 14- $\alpha$-demethylase) on the ergosterol biosynthesis pathway. Here, we demonstrate that a point mutation K143R in ERG11 (C. albicans ERG11 K143R/K143R) contributes not only to azole resistance, but causes increased gene expression. Overexpression of ERG11 results in increased ergosterol content and a significant reduction in plasma membrane fluidity. Simultaneously, the same point mutation caused cell wall remodeling. This could be facilitated by the unmasking of chitin and $\beta$-glucan on the fungal cell surface, which can lead to recognition of the highly immunogenic $\beta$-glucan, triggering a stronger immunological reaction. For the first time, we report that a frequently occurring azole-resistance strategy makes $C$. albicans less susceptible to azole treatment while, at the same time, affects its cell wall architecture, potentially leading to exposure of the pathogen to a more effective host immune response.
\end{abstract}

Keywords: Candida albicans; ergosterol; plasma membrane; cell wall

\section{Introduction}

Candida albicans (C. albicans) constitutes a natural part of the human microbiome. However, in cases of immunodeficiency, it can cause an opportunistic infection called candidiasis [1]. According to a Centers for Disease Control and Prevention (CDC) report, there are approximately 25,000 cases of candidemia (blood infection caused by Candida sp.) each year, and C. albicans remains the dominant species isolated from the patient population [2,3]. Large numbers of Candida-related infections, along with ineffective treatment, lead to a high mortality rate among patients suffering from candidemia (38-75\%) [4]. The major problem during anticandidal therapy is a worldwide resistance of Candida sp. to commonly used antifungals [5]. This is due to widely used antifungals, e.g., azoles, clinically implemented in the 1980s [6]. Decades of azole usage has led to the development of effective defense mechanisms to avoid the toxic activity of antifungals.

Azoles (e.g., fluconazole, ketoconazole) inhibit the activity of lanosterol 14- $\alpha$-demethylase (Erg11p, encoded by the ERG11 gene), a key enzyme of the ergosterol biosynthesis pathway [7]. Ergosterol constitutes a component of the fungal plasma membrane (PM) which is important for its functionality and the maintenance of its structural properties [8]. A diminished amount of ergosterol and the accumulation of toxic $14-\alpha$-methylated sterols in 
fungal PM after azole therapy contributes to pathogen growth inhibition [9]. The fact that azole drugs are not fungicidal but fungistatic is one of the disadvantages of azole usage and contributes to the creation of vast numbers of resistance mechanisms. An example of the resistance mechanism is the presence of point mutations in ERG11 (especially near the active site of the enzyme), resulting in a decreased binding affinity of the azoles to Erg11p [7,10]. Another azole resistance strategy is an altered sterol composition in the PM of C. albicans and increased expression of ERG11 due to the upregulation of its transcription factor UPC2, and the overexpression of the genes encoding multidrug resistance transporters (e.g., CDR1, CDR2) [10,11].

In contrast to azoles, polyenes (e.g., amphotericin $\mathrm{B}(\mathrm{AMB})$, nystatin) are fungicidal and bind directly to the ergosterol present in C. albicans PM [5]. Polyenes induce the formation of pores in the PM, leading to ion leakage and cell death [12]. Due to the characteristic mode of action of the polyenes, the resistance of clinical isolates remains a very rare event, but it can be achieved by depriving the pathogen PMs of ergosterol [13]. Other drugs that are employed in antifungal therapy are echinocandins (e.g., caspofungin) that act on the $C$. albicans cell wall (CW), affecting glucan synthesis [14]. Furthermore, caspofungin causes significant $\beta$-glucan exposure on the $C$. albicans cell surface, resulting in an increased phagocytic response by the dendritic cells [15]. The $C$. albicans $C W$ consist of three components: chitin, $\beta$-glucan, and a thick layer of mannoproteins [16]. Typically, chitin and $\beta$-glucan are located within the inner $\mathrm{CW}$, providing shape and strength [17]. Meanwhile, the outer layer of the $\mathrm{CW}$ is composed of mannans and cell wall proteins (CWPs) that are glycosylphosphatidylinositol (GPI)-anchored in the inner chitin/ $\beta$-glucan core [18]. Recently, we have reported that the deprivation of ergosterol (as a consequence of ERG11 gene deletion) from the C. albicans PM corresponds to $\beta$-glucan unmasking on the CW surface [19]. This suggests that the presence of ergosterol in fungal PM is crucial for maintaining the $\mathrm{CW}$ composition, and changes in the $\mathrm{CW}$ structure can lead to diverse host immune responses to the pathogen.

Considering the importance of ergosterol as a drug target, we investigated the influence of a nonsynonymous point mutation (K143R/K143R) in the ERG11 gene on the PM and $\mathrm{CW}$ of $\mathrm{C}$. albicans. This mutation was chosen since it was discovered in fluconazole-resistant Candida sp. clinical isolates [20,21]. Here, we report that the introduction of the point mutation in ERG11 correlates with the increased expression of this gene. The overexpression of the ERG11 gene results in a significantly higher ergosterol content in the PM, which increases the resistance of the fungus to commonly used antifungal drugs (e.g., fluconazole (FLC)). We also compare the sterol profile of C. albicans ERG11 ${ }^{K 143 R / K 143 R}$ with the $C$. albicans $\operatorname{erg} 11 \Delta / \Delta$ strain that was previously investigated by our team [22]. We demonstrate that both the deprivation and the elevated content of ergosterol contribute to the increased fluidity of C. albicans PM. Furthermore, our recent findings show that a lack of ergosterol in C. albicans PM caused chitin and $\beta$-glucan exposure [19], and so it is relevant to explore the influence of the K143R substitution on the C. albicans cell morphology. Our investigations revealed that the point mutation in ERG11, as well as the gene deletion, result in chitin and $\beta$-glucan unmasking on the cell surface, highlighting the crucial role of ergosterol for maintaining the PM integrity and CW architecture. Our data show that alterations in the ergosterol content in C. albicans PM can also correspond to significant changes in the immune response profile following antifungal therapy during a pathogen infection. $\beta$-glucan is a highly immunogenic pathogen-associated molecular pattern (PAMP) recognized by pattern recognition receptors (PRRs) (e.g., dectin-1) present on the host cell surface [23]. Unmasking of PAMPs on the fungal cell surface can result in the changed host immune response by triggering the production of a different cytokine profile [24]. 


\section{Results}

2.1. Point Mutation in ERG11 Does Not Affect the Growth of the C. albicans ERG11 K143R/K143R Strain and Contributes to Increased Fluconazole Resistance

In order to investigate the impact of an introduced point mutation in ERG11 gene $(K 143 R / K 143 R)$, we performed the growth curve and the azole susceptibility test for the $C$. albicans ERG11 K143R/K143R (10C1B1I1) strain. The results were compared to those obtained for the C. albicans strain which lacks the ERG11 gene (KS058).

We observed that a point mutation (K143R/K143R) in ERG11 of C. albicans 10C1B111 did not affect the growth of this strain, and no temporal shift in growth phases was observed (Figure 1A). As opposed to C. albicans 10C1B1I1, the KS058 strain $(\operatorname{erg} 11 \Delta / \Delta)$ exhibited a significantly lower growth rate compared to the $C$. albicans WT strain. This impaired growth of C. albicans $\operatorname{erg} 11 \Delta / \Delta$ was previously reported by our team, but for the parental CAF2-1 strain [22]. Interestingly, the single amino acid replacement in Erg11p contributes to the decreased susceptibility of C. albicans 10C1B1I1 to FLC (IC50 eight times higher than for WT), but not to amphotericin B (AMB) (Figure 1B), and this is likely due to the less-effective binding of azole to the active site of the enzyme. Considering that $C$. albicans KS058 lacks targets for both FLC (Erg11p) and AMB (ergosterol), the ERG11 gene deletion correlates with resistance toward the investigated antifungals.

A

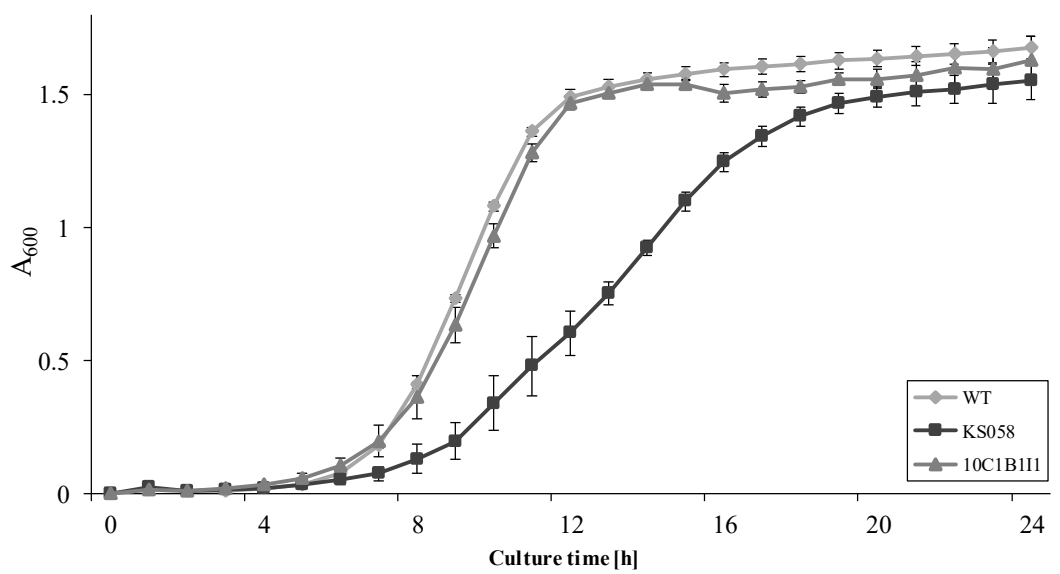

B
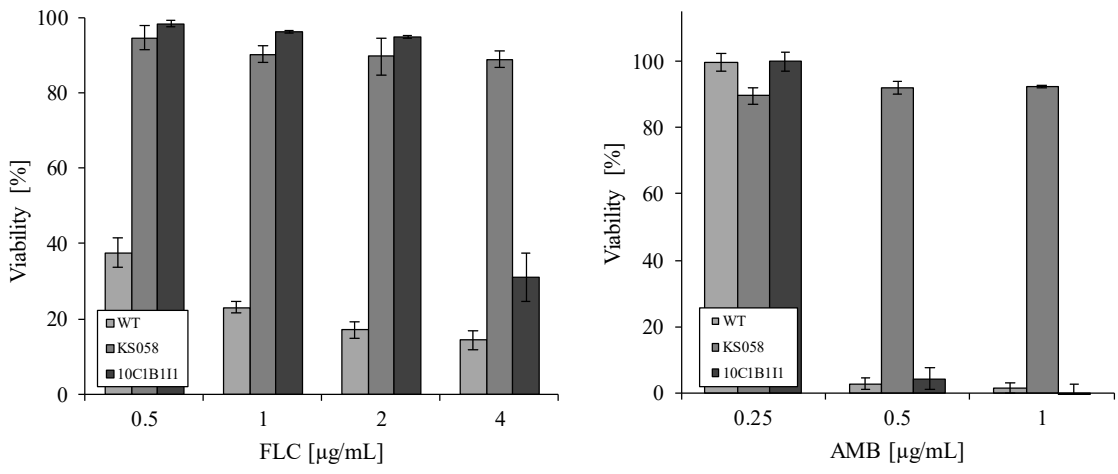

Figure 1. (A) The growth curve of the C. albicans SC5314 wild type (WT), $\operatorname{erg} 11 \Delta / \Delta$ (KS058) and the ERG11 ${ }^{K 143 R / K 143 R}$ (10C1B1I1) strains in a YPD medium $\left(28^{\circ} \mathrm{C}, 120 \mathrm{rpm} ; n=3, \pm \mathrm{SD}\right)$. (B) The percent viability of the C. albicans WT, KS058, and 10C1B1I1 strains cultured for $24 \mathrm{~h}, 28^{\circ} \mathrm{C}$, in a YPD medium supplemented with FLC (left) or AMB (right) $(n=3, \pm \mathrm{SD})$.

2.2. The Point Mutation ERG11 ${ }^{K 143 R / K 143 R}$ Results in an Increased ERG11 Gene Expression in the C. albicans 10C1B1I1 Strain

Taking into account that introducing the K143R/K143R point mutation in ERG11 resulted in a decreased sensitivity toward FLC, we decided to investigate whether it will also affect the ERG11 gene expression at different phases of growth $(8,14$ and $24 \mathrm{~h})$ and 
after FLC or AMB treatment (Figure 2). The concentrations of FLC $(4 \mu \mathrm{g} / \mathrm{mL})$ and AMB $(0.25 \mu \mathrm{g} / \mathrm{mL})$ were selected based on the viability test (Figure $1 \mathrm{~B})$, and these are IC50 (for FLC), or two times lower than the IC50 (for AMB) for the 10C1B1I1 strain.

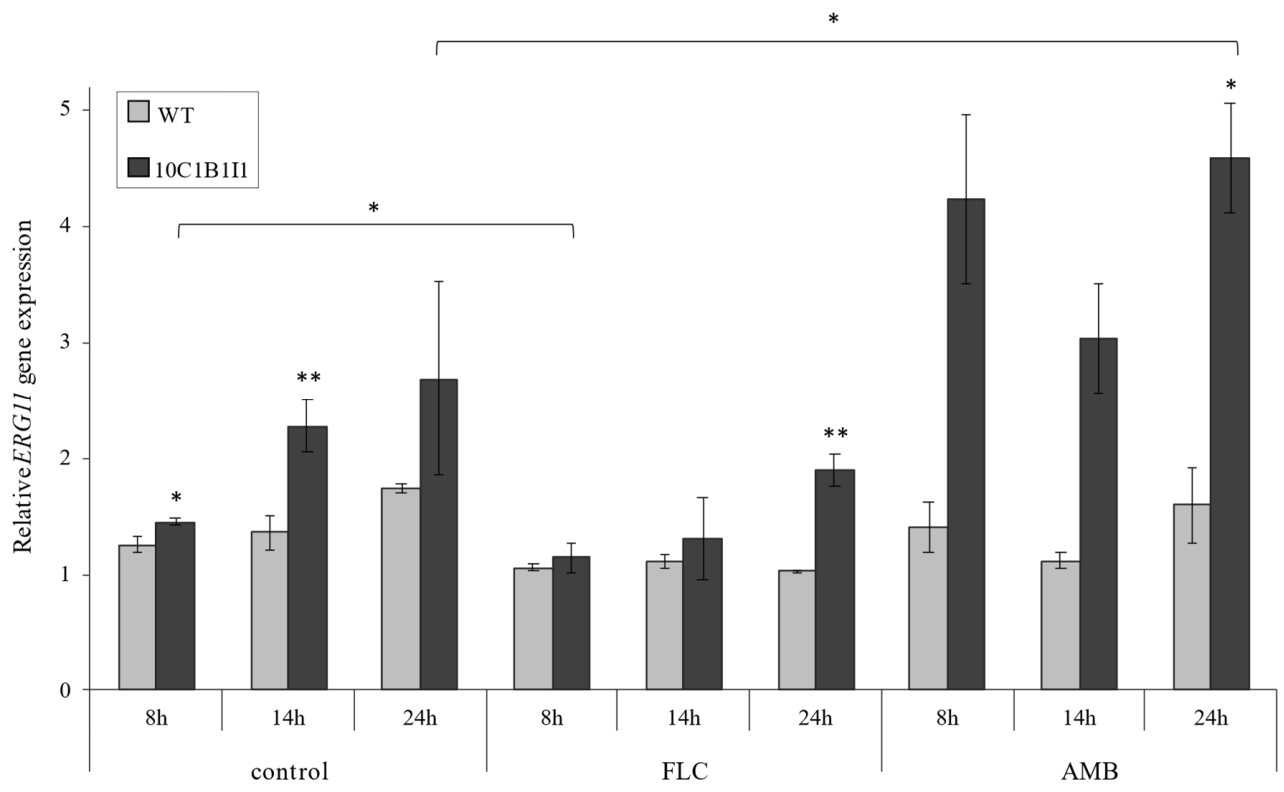

Figure 2. The relative ERG11 gene expression in the C. albicans SC5314 wild type (WT) and ERG11 ${ }^{K 143 R / K 143 R}$ (10C1B1I1) strains determined for different growth times $(8,14$, and $24 \mathrm{~h})$ and culture conditions: control (YPD medium alone), and with the addition of FLC $(4 \mu \mathrm{g} / \mathrm{mL})$ or AMB $(0.25 \mu \mathrm{g} / \mathrm{mL}) ; \pm \mathrm{SD} ; n=3$. Statistical analysis was performed by comparing the expression of the $C$. albicans WT and 10C1B1I1, or between the different culture conditions $\left({ }^{*}, p<0.05 ;{ }^{* *}, p<0.01\right)$.

Our analysis revealed that the C. albicans 10C1B1I1 strain exhibits an increased ERG11 gene expression under control conditions (YPD medium alone) in the early $(8 \mathrm{~h})$ and late $(14 \mathrm{~h})$ logarithmic growth phases. After treatment with FLC, the ERG11 expression was slightly reduced compared to the control conditions at $8 \mathrm{~h}$ of growth for the C. albicans 10C1B1I1 strain. However, at the stationary growth phase $(24 \mathrm{~h})$, the ERG11 expression in 10C1B1I1 was two-fold higher than in the WT strain. Interestingly, the treatment of the 10C1B1I1 strain with AMB resulted in a significantly higher ERG11 gene expression in the stationary growth phase (three-fold higher than WT strain). The expression of ERG11 is also significantly higher following $24 \mathrm{~h}$ of culture after the AMB treatment than in the control conditions (Figure 2).

\subsection{The Overexpression of the ERG11 Gene Corresponds to an Elevated Ergosterol Content in the C. albicans ERG11 K143R/K143R Strain}

We decided to further investigate whether the overexpression of ERG11 in the 10C1B1I1 strain contributes to an increased level of ergosterol. In order to verify whether the $K 143 R / K 143 R$ point mutation in the ERG11 gene resulted in an altered sterol profile of C. albicans, we performed GC-MS analysis. We performed the same analysis for C. albicans $\operatorname{erg} 11 \Delta / \Delta$ in order to compare our results with those obtained for $C$. albicans

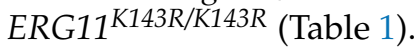

At the early logarithmic $(8 \mathrm{~h})$ growth phase, the level of ergosterol in 10C1B1I1 was comparable to the WT strain. In both cases, level of ergosterol significantly increased with culture aging and the ergosterol content in PM of the C. albicans 10C1B1I1 strain at $14 \mathrm{~h}$ was 1.9-fold higher than the WT strain (93.82 and $49.49 \mu \mathrm{g} / \mathrm{mg}$, respectively). The level of ergosterol decreased in both strains during the stationary phase growth $(24 \mathrm{~h})$, but for the 10C1B1I1 strain, the levels remained 1.3-fold higher than for WT strain (37.18 and $28.82 \mu \mathrm{g} / \mathrm{mg}$, respectively) (Table 1 ). 
Table 1. The sterol analysis ( $\mu \mathrm{g} / \mathrm{mg}$ of the dry mass of isolated lipids; $\pm \mathrm{SD} ; n=3$; ND-not detected) determined for the $C$. albicans SC5314 wild type (WT), ERG11 K143R/K143R (10C1B1I1), and erg11 $/ \Delta$ (KS058) strains in different growth times $(8,14$ and $24 \mathrm{~h})$ and under different culture conditions: control (YPD medium alone), with the addition of FLC $(4 \mu \mathrm{g} / \mathrm{mL})$, or AMB $(0.25 \mu \mathrm{g} / \mathrm{mL})$. The sterol content was determined using the GC-MS method. Statistical analysis was performed by comparing the amounts of specific sterols in 10C1B1I1 or KS058 against the WT strain at each time point and under each culture condition $\left({ }^{*}, p<0.05 ;{ }^{* *}, p<0.01 ;{ }^{* * *}, p<0.001\right)$.

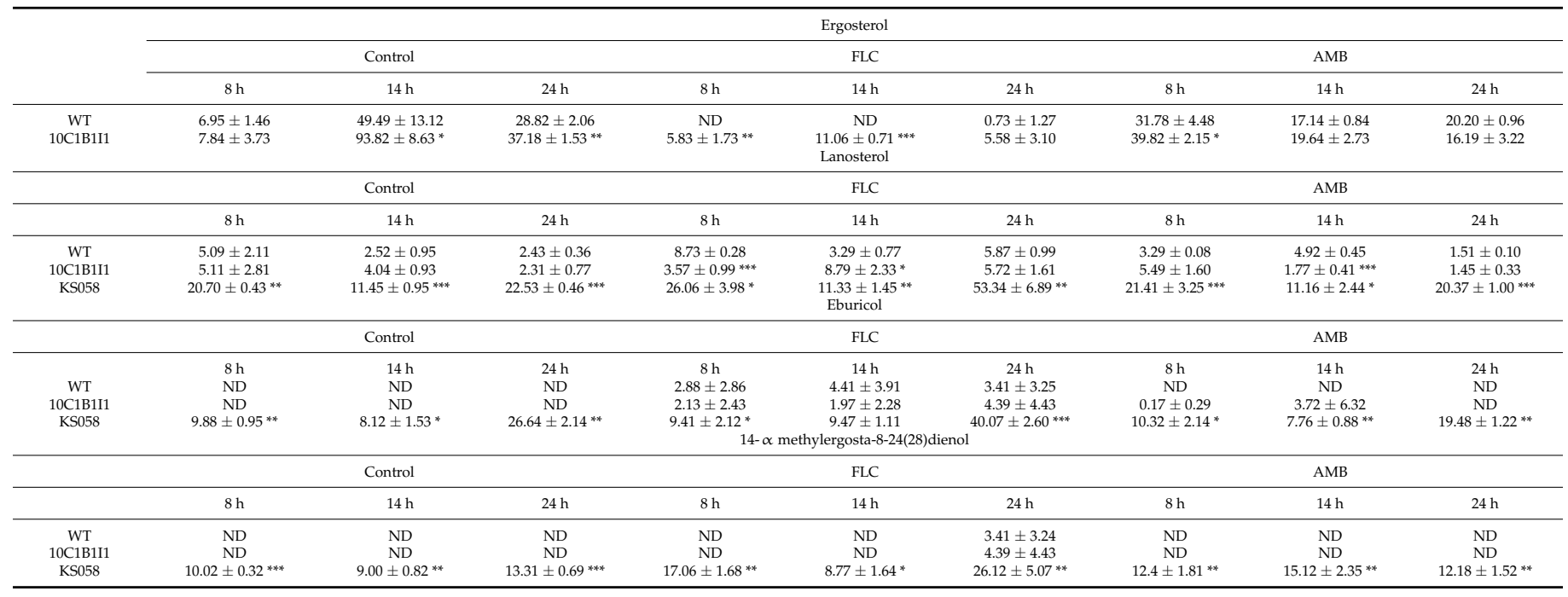

The FLC treatment resulted in an absence of ergosterol in the PM of the C. albicans WT strain in all growth phases, although a trace amount of ergosterol was found in the PM of the WT cells in the stationary growth phase $(0.73 \mu \mathrm{g} / \mathrm{mg})$. For the C. albicans $10 \mathrm{C} 1 \mathrm{~B} 1 \mathrm{I1}$ cells, the level of ergosterol found in an $8 \mathrm{~h}$ culture after FLC treatment was comparable to those found in the control conditions ( 5.83 and $7.84 \mu \mathrm{g} / \mathrm{mg}$, respectively). A significant decrease in the ergosterol level was observed in both $14 \mathrm{~h}$ and $24 \mathrm{~h}$ of 10C1B1I1 growth $(82.2$ and $85 \%$ decrease in ergosterol, respectively; $p<0.001$ ) compared to control conditions.

The addition of AMB to both the WT and 10C1BI1 cultures resulted in a significant increase in ergosterol in the $8 \mathrm{~h}$ growth phase compared to the control conditions (around 5 -fold change in the ergosterol content for both C. albicans strains). For C. albicans 10C1B1I1, this may be the consequence of the overexpression of ERG11 (Figure 2). The ergosterol level in the 10C1B1I1 strain treated with AMB decreased with the aging of the culture and was comparable to the WT strain.

Our results also demonstrate a significantly higher lanosterol content for the C. albicans KS058 strain in control conditions (four-fold higher at $8 \mathrm{~h}$ of culture compared to the WT and 10C1B1I1 strains). At $14 \mathrm{~h}$ of culture, a lower lanosterol content was noted for the WT and 10C1B1I1 strains (2.52 and $4.04 \mu \mathrm{g} / \mathrm{mg}$, respectively) and its level was comparable to that obtained for the $24 \mathrm{~h}$ cultures. At both culture times $(14 \mathrm{~h}$ and $24 \mathrm{~h}$ of culture), lanosterol concentration was significantly higher for the KS058 strain (11.45 and $22.53 \mu \mathrm{g} / \mathrm{mg}$, respectively; $p<0.001)$ compared to the WT and 10C1B1I1 strains.

During our investigations, eburicol was detected only after the AMB treatment of 10C1B1I1 at $8 \mathrm{~h}$ and $14 \mathrm{~h}$ of culture and after the FLC treatment for both the WT and 10C1B1I1 strains. However, elevated levels of eburicol were observed for the KS058 strain when compared to the WT and 10C1B1I1 strains in all investigated conditions. The eburicol content at $8 \mathrm{~h}$ and $14 \mathrm{~h}$ in the KS058 strain culture exhibited similar levels (9.41 and $9.47 \mu \mathrm{g} / \mathrm{mg}$, respectively) and increased at $24 \mathrm{~h}$ of culture $(40.07 \mu \mathrm{g} / \mathrm{mg})$.

Levels of 14- $\alpha$ methylergosta-8-24(28)dienol were detected in all culture conditions for the $C$. albicans KS058 strain, while for the WT and 10C1B1I1 strains, it was only detected at $24 \mathrm{~h}$ of culture after the FLC treatment. Similar to lanosterol, an increased level of $14-\alpha$ methylergosta-8-24(28)dienol was also observed previously by our team in C. albicans 
KS028 [22]. However, the level of 14- $\alpha$ methylergosta-8-24(28)dienol detected in the KS058 strain (parental to the SC5314 strain) was lower compared to the KS028 strain (parental to CAF2-1 strain).

\subsection{An Increased Ergosterol Content in C. albicans ERG11 ${ }^{K 143 R / K 143 R}$ Results in Decreased Plasma Membrane Fluidity}

To investigate whether an increased ergosterol content in the C. albicans 10C1B1I1 strain leads to altered PM fluidity, we measured the fluorescence of a Laurdan probe incorporated to the PM of the C. albicans cells of all strains analyzed in this work (Table 2).

Table 2. The general polarization values (GP; means $\pm \mathrm{SD}, n=6)$ for a Laurdan fluorescent probe incorporated into the plasma membrane of the C. albicans SC5314 (WT), erg11 $/ \Delta$ (KS058), and ERG11 ${ }^{K 143 R / K 143 R}$ (10C1B1I1) strains. For the experiment, culturing was performed in a YPD medium (control conditions), at $28{ }^{\circ} \mathrm{C}, 120 \mathrm{rpm}$, for $8 \mathrm{~h}$ or $24 \mathrm{~h}$, with the addition of FLC $(4 \mu \mathrm{g} / \mathrm{mL})$ or AMB $(0.25 \mu \mathrm{g} / \mathrm{mL})$. A statistical analysis was conducted in accordance to the GP values for the WT strain after specific culture times $\left({ }^{*}, p<0.05 ;{ }^{* *}, p<0.01 ;{ }^{* * *}, p<0.001\right)$.

\begin{tabular}{ccccccc}
\hline & \multicolumn{2}{c}{ Control } & \multicolumn{2}{c}{ FLC } & \multicolumn{2}{c}{ AMB } \\
\hline & $\mathbf{8 h}$ & $\mathbf{2 4} \mathbf{h}$ & $\mathbf{8 h}$ & $\mathbf{2 4} \mathbf{h}$ & $\mathbf{8 ~ h}$ & $\mathbf{2 4} \mathbf{h}$ \\
\hline WT & $-0.33 \pm 0.046$ & $-0.07 \pm 0.111$ & $-0.31 \pm 0.049$ & $-0.35 \pm 0.026$ & $-0.37 \pm 0.038$ & $-0.38 \pm 0.029$ \\
KS058 & $-0.21 \pm 0.026^{* * *}$ & $-0.09 \pm 0.122$ & $-0.29 \pm 0.069$ & $-0.34 \pm 0.017$ & $-0.37 \pm 0.040$ & $-0.36 \pm 0.049$ \\
10C1B1I1 & $-0.10 \pm 0.036^{* * *}$ & $0.05 \pm 0.023^{*}$ & $-0.26 \pm 0.085$ & $-0.32 \pm 0.015$ & $-0.28 \pm 0.021^{* *}$ & $-0.35 \pm 0.077$ \\
\hline
\end{tabular}

Our analysis showed that the $C$. albicans KS058 and 10C1B1I1 strains at $8 \mathrm{~h}$ of culture exhibit significantly higher GP values ( -0.21 and -0.10 , respectively), highlighting the correlation between both the deprivation and the overproduction of ergosterol and decreased PM fluidity. The representative, normalized fluorescence intensities spectra for the investigated strains in $8 \mathrm{~h}$ or $24 \mathrm{~h}$ of culture are presented in Figure 3.
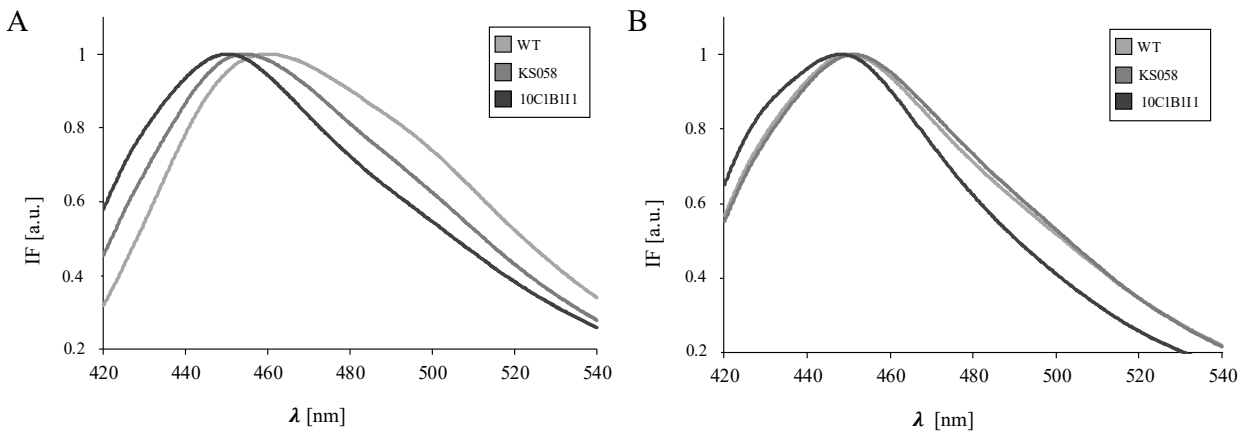

Figure 3. The representative, normalized fluorescence intensities (IFs) spectra for a Laurdan fluorescent probe incorporated into the plasma membrane of the C. albicans SC5314 (WT), erg $11 \Delta / \Delta$ (KS058), and $E R G 11^{K 143 R / K 143 R}$ (10C1B1I1) strains in control conditions at $8 \mathrm{~h}(\mathbf{A})$ and $24 \mathrm{~h}(\mathbf{B})$.

For C. albicans KS058 and 10C1B1I1, we detected a red shift for Laurdan IF at $8 \mathrm{~h}$ of culture (Figure 3A). The PM fluidity of the investigated strains decreased significantly at $24 \mathrm{~h}$ of culture (Table 2) and this was expressed in a deepened red shift of the Laurdan IFs (Figure 3B). However, the overproduction of ergosterol in the 10C1B1I1 strain resulted in 1.4-fold lower fluidity of the PM (positive GP value) comparing to the WT and KS058 strains.

\subsection{The Deletion and Increased Expression of the C. albicans ERG11 Gene Correlates with CW Remodeling}

In order to verify whether the increased production of ergosterol in the 10C1B1I1 strain of $C$. albicans contributes to $\mathrm{CW}$ remodeling, we performed staining for all three components (chitin, $\beta$-glucan, and mannan) (Figure 4). 
A
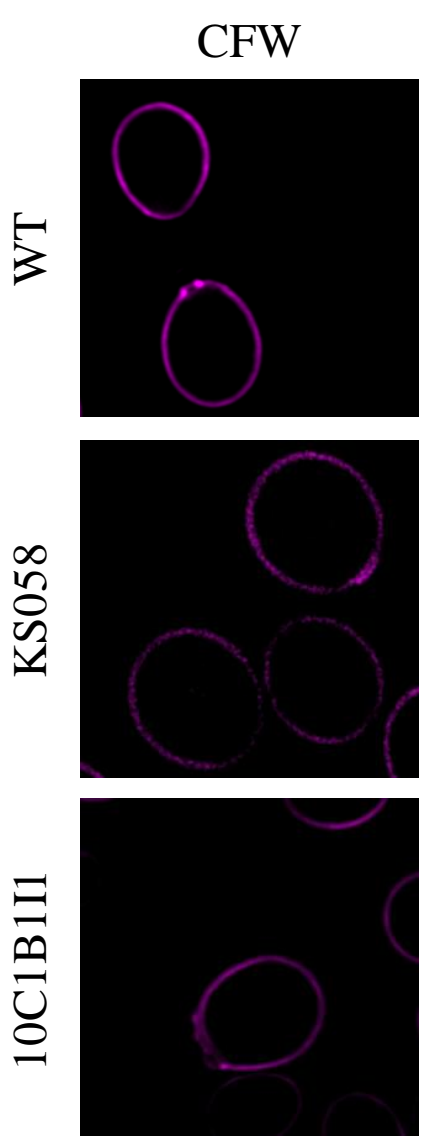

FC-Dec1
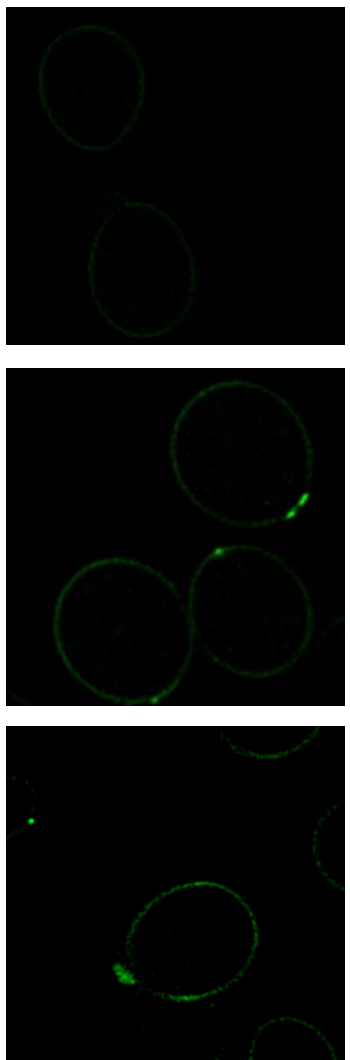
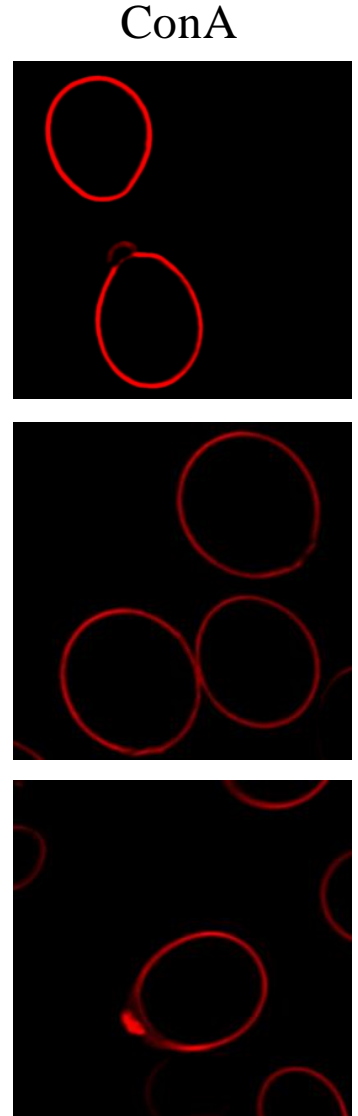
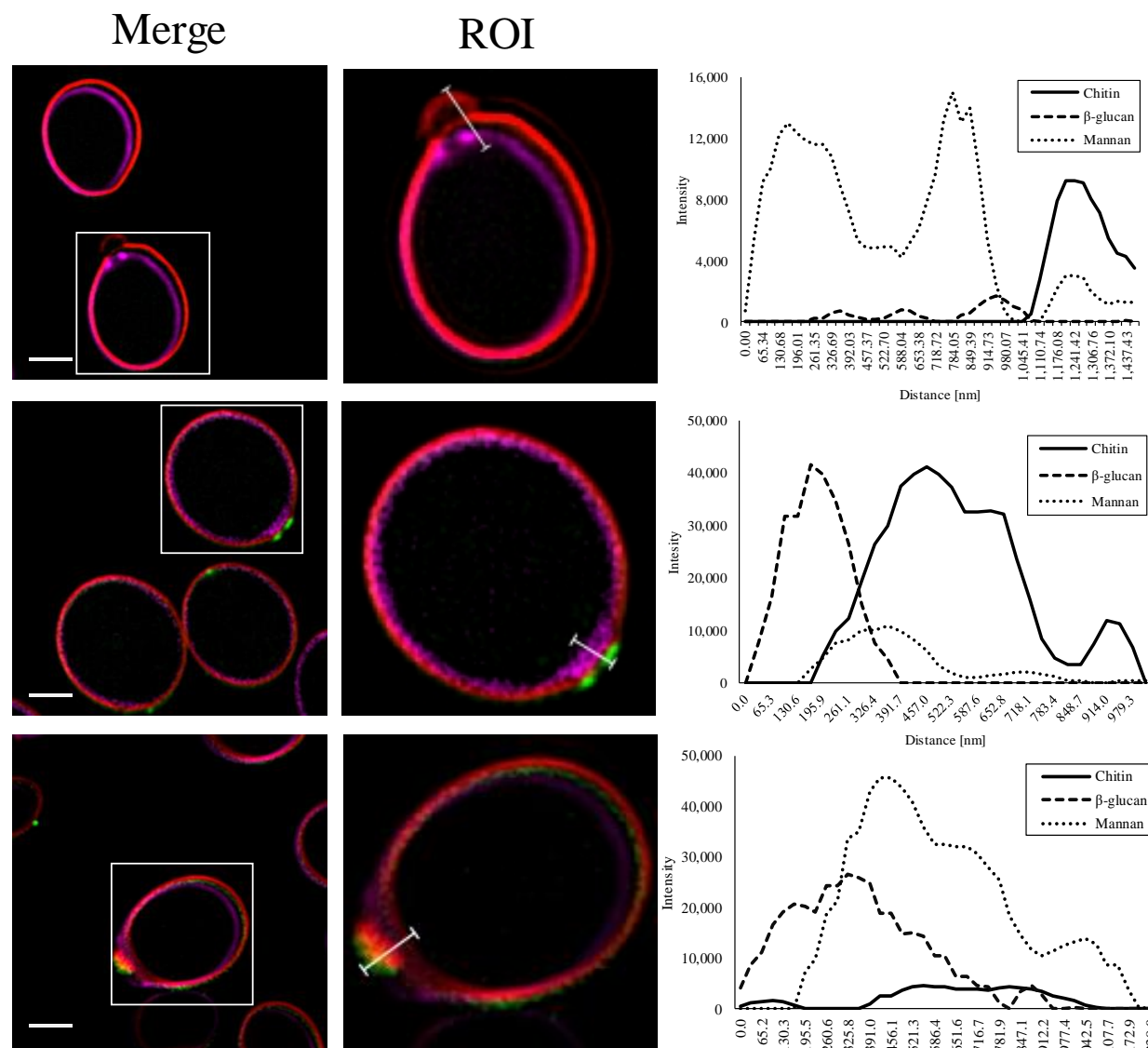

B

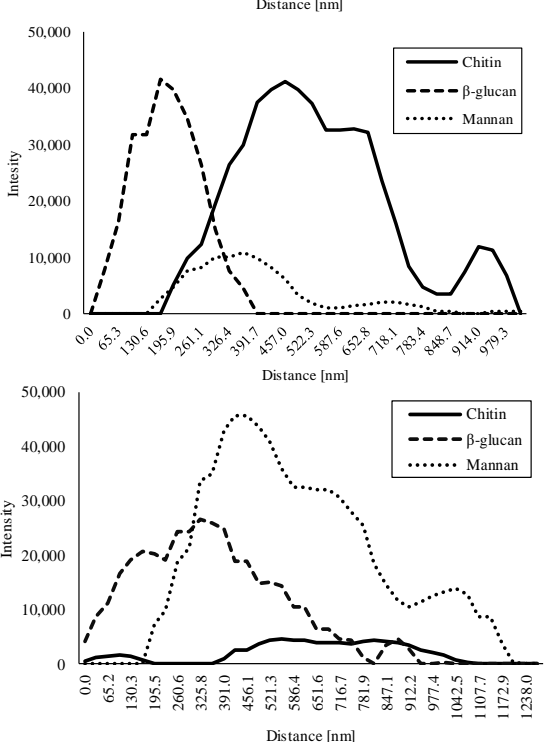

Figure 4. Triple staining of the C. albicans cell wall components for the SC5314 wild type (WT), erg11 $/ \Delta$ (KS058), and ERG11 K143R/K143R (10C1B1I1) strains (A). Total chitin was detected using calcofluor white (CFW) (purple). Exposed $\beta$-glucan was stained with Fc-hDectin-1 (FC-Dec1) and Alexa Fluor 448-conjugated anti-human IgG Fc antibodies (green). Mannans were detected using streptavidin and concanavalin A (ConA) conjugated with Alexa Fluor-568 (red). Scale bars of all presented images are equal to $2 \mu \mathrm{m}$. White squares on the merged picture represent region of interest (ROI). Fluorescence intensities for particular CW components for ROI (regions of bud scars; white lines) for investigated C. albicans strains (B). The distance [nm] between CW components is presented from outside to inside of the cell at the area of the bud scars. 
Microscopic study revealed that chitin is typically located in the inner part of the CW of the C. albicans WT strain, covered by a thick layer of mannans (Figure 4A). A different situation was observed for the KS058 strain, where the chitin layers overlap with the mannans. At the bud scars, there was a pointwise fluorescence signal from the exposed $\beta$-glucan. This demonstrate that chitin and $\beta$-glucan could be partially unmasked in the KS058 strain, and unmasked chitin was observed in the region of the bud scar of the 10C1B1I1 strain. Similar to the KS058 strain, the exposed $\beta$-glucan accumulation was detected within the bud scar of the 10C1B1I1, but the fluorescence signal was also present along the full fungal cell length. In addition, we determined the exposure rate of the chitin and $\beta$-glucan at the bud scars for C. albicans WT, KS058, and 10C1B1I1 (Figure 4B).

Analysis revealed that changes in the PM caused by the altered ergosterol level correlates with the remodeling of $C$. albicans $C W$. $\beta$-glucan, typically hidden under the mannoprotein layer (C. albicans WT), was unmasked in both the C. albicans KS058 and 10C1B1I1 strains at the region of the bud scar (Figure 4B). In the case of the C. albicans WT strain, chitin was located in the inner part of the CW. Opposite to the WT, for both C. albicans strains with the depletion and overproduction of ergosterol, we observed a shift of the chitin layer to the outer part of the $\mathrm{CW}$, and it partially overlapped with the mannans and the $\beta$-glucan.

We also performed a FACS analysis to verify the amount of particular CW components (unmasked chitin, $\beta$-glucan, and mannans) present after $24 \mathrm{~h}$ of culture (Figure 5 ).
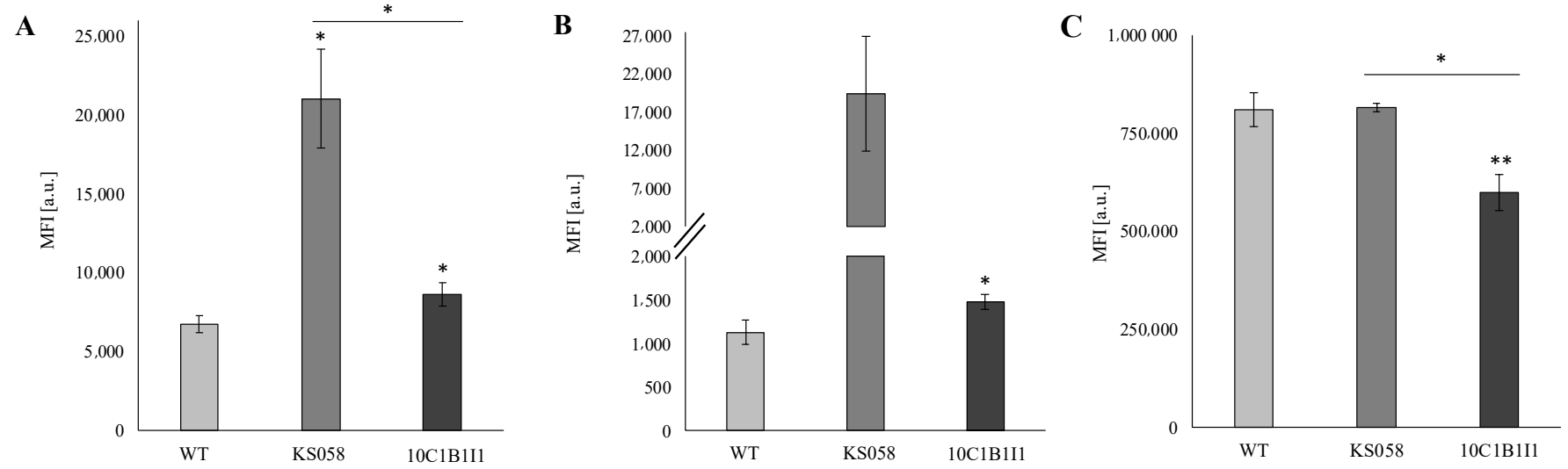

Figure 5. The exposure of chitin (panel (A)), $\beta$-glucan (panel (B)), and mannans (panel (C)) in the C. albicans SC5314 wild type (WT), erg11 $/ \Delta$ (KS058) and ERG11 ${ }^{K 143 R / K 143 R}$ (10C1B111) strains grown for $24 \mathrm{~h}$ in YPD $\left(28^{\circ} \mathrm{C}, 120 \mathrm{rpm}\right)$. In each case, the $C$. albicans cells were stained with wheat germ agglutinin conjugated with FITC (WGA-FITC; in case of exposed chitin, panel (A)), Fc-hDectin-1 and Alexa Fluor 448-conjugated anti-human IgG Fc antibodies (in the case of unmasked $\beta$-glucan, panel (B)) or streptavidin and concanavalin A (ConA) conjugated with Alexa Fluor 568 (in case of mannans, panel (C)) and analyzed by FACS. Median fluorescence intensities (MFIs) were quantified for three independent experiments. Statistical analyses were performed using the WT strain, or between KS058 and 10C1B1I1 (above lines) $(*, p<0.05 * *, p<0.01)$.

Analysis revealed the significant exposure of chitin and $\beta$-glucan in both the KS058 and 10C1B1I1 strains. This is supported by the detection of $\beta$-glucan signals in the most exposed fragment of KS058 and 10C1B1I1 CW in contrast to the WT (Figure 5). In the case of unmasked chitin (Figure 5A), we observed an MFI value for KS058 and 10C1B1I1 that is 3-fold and 1.3-fold higher, respectively, than for the WT strain, while exposed $\beta$-glucan MFIs are 17-fold and 1.3-fold higher for the KS058 and 10C1B1I1 strains, respectively (Figure 5B). This may be related to the local accumulation of unmasked $\beta$-glucan in the bud scars region of KS058. Our research indicates that the 10C1B1I1 strain possess a decreased amount of mannans (MFI 1.4-fold lower than the WT and KS058 strains; Figure 5C). Herein, 
we also demonstrated that increased ergosterol contributes to chitin and $\beta$-glucan exposure on the outside of the fungal cell, as well to a decreased mannan content (Figures 4 and 5).

\section{Discussion}

One of the most common azole-resistance strategies of $C$. albicans is introducing a point mutation in the gene (ERG11) encoding enzyme Erg11p — the target for azole drugs [7]. The K143R amino-acid substitution in Erg11p is considered to be responsible for alterations to the tertiary structure of Erg11p, resulting in a lower binding affinity of azoles to this enzyme [25]. This is due to the fact that lysine K143 is located in the exposed active-site cavity of the enzyme, and amino-acid replacement in this hot-spot region could correspond to conformational change in the protein [26]. Our research revealed that this single aminoacid substitution caused increased resistance toward FLC, but not to AMB (Figure 1B), indicating the role of the $K 143 R / K 143 R$ point mutation in resistance toward first-choice antifungals such as azoles. Furthermore, the lysine 143 substitutions (e.g., K143R and K143Q) were also identified in the azole-resistant Candida spp. clinical isolates [20,24], demonstrating the importance of this amino-acid for the proper binding of azoles to Erg11p.

Our analysis also revealed a higher expression of the ERG11 gene particularly in the $8 \mathrm{~h}$ and $14 \mathrm{~h}$ of culture (Figure 2). The increased ERG11 gene expression and the reduced azole susceptibility were associated with the upregulation of the transcription factor (TF) of this gene (e.g., UPC2) [27]. In the case of K143R substitution, it is highly unlikely that TF has an influence on the increased expression of ERG11, as UPC2 binds the ERG11 promoter sequence [28]. Nevertheless, synonymous codon substitutions in ERG11 were shown to lead to the increased expression of the ERG11 gene in C. krusei [29]. Thus, a similar situation can occur in the case of K143R substitutions in Erg11p. The increased expression of the ERG11 gene after FLC or AMB treatment (Figure 2) could be the result of a stress response due to used antifungals. Here, we report for the first time that K143R substitution in Erg11p not only confer FLC resistance, but also cause an increase in the expression of the ERG11 gene, leading to higher ergosterol production during FLC treatment.

Furthermore, sterol analysis revealed the significant increase in the ergosterol content in the late logarithmic and stationary phases of growth in C. albicans ERG11 K143/K143R (Table 1). Taking this into account, the increased ERG11 gene expression in the early and late logarithmic growth phases correlates with an elevated ergosterol content.

Current work demonstrates that point mutation in ERG11 results not only in a lower susceptibility to FLC, but also contributes to higher levels of ergosterol after FLC treatment (Table 1). The addition of FLC $(4 \mu \mathrm{g} / \mathrm{mL})$ results in the absence of ergosterol in C. albicans WT, but not in C. albicans ERG11 ${ }^{K 143 / K 143 R}$. This could be the consequence of an increased expression of the ERG11 gene and the overall elevated level of Erg11p. Furthermore, the inhibition rate for the mutated form of an enzyme is not as effective as for the WT form of the protein [30]. Therefore, the K143R substitution not only contributes to higher ERG11 expression (Figure 2), but also provides FLC resistance because of an elevated level of ergosterol.

The data demonstrates that increased levels of ergosterol do not contribute to AMB resistance. Cellular stress caused by AMB results in the elevated production of ergosterol in the early growth phases of AMB treatment. Conversely, supplementation of the C. albicans culture with ergosterol in the presence of $\mathrm{AMB}$ had been shown to inhibit the release of $\mathrm{K}^{+}$ ions from fungal cells [31]. Our analysis revealed that the K143R substitution contributes to increased FLC resistance (Figure 1B); however, in cultures treated with AMB, this mutation leads to the overproduction of ergosterol, resulting in the enhanced binding of AMB to the C. albicans cell and the sensitization of the fungal cells to polyenes [32].

After 24 h culture of $C$. albicans $\operatorname{erg} 11 \Delta / \Delta$, about a 10-fold increase of lanosterol was detected compared to the WT strain (Table 1). This suggests that the lack of ergosterol in the $\operatorname{erg} 11 \Delta / \Delta$ strain is compensated by the presence of increased lanosterol in the PMs. An elevated lanosterol content was previously described by our team, but for the C. albicans KS028 strain $(\operatorname{erg} 11 \Delta / \Delta$, isogenic to the CAF2-1 parental strain) [22]. KS058 lacks the targets 
for FLC and AMB (Erg11p and ergosterol, respectively), so treatment of the KS058 strain with FLC and AMB would not contribute to a significant change in the lanosterol content in any of the culture conditions except for the $24 \mathrm{~h}$ of culture after FLC treatment. In this condition, a two-fold increase in the lanosterol content was observed compared to control conditions. Furthermore, depriving C. albicans PM of ergosterol results in the presence of both eburicol and 14- $\alpha$ methylergosta-8-24(28)dienol (Table 1). For C. albicans erg $11 \Delta / \Delta$, the consequence of the interruption of ergosterol production is the accumulation of lanosterol. This sterol is converted by $\Delta(24)$-sterol C-methyltransferase (Erg6p) into eburicol, then by D5,6-desaturase (Erg3p) into 14- $\alpha$ methylergosta-8-24(28)dienol [33]. This explains the presence of eburicol, 14-methylergosta-8,24-diendiol, and an elevated concentration of lanosterol in the KS058 strain. Low concentrations of eburicol were found in the WT and 10C1B1I1 strains only after FLC treatment, or after $8 \mathrm{~h}$ and $14 \mathrm{~h}$ of cultures with AMB for the 10C1B1I1 strain. 14- $\alpha$ methylergosta-8-24(28)dienol was present only after a $24 \mathrm{~h}$ culture with FLC for the WT and 10C1B1I1 strains, and its level was around six-fold lower than for C. albicans KS058.

Considering the alterations in the PM sterol profile shown in this work, we decided to determine the impact of these changes on the PM properties. Our analysis of the PM fluidity of C. albicans indicated significantly higher GP values for the C. albicans KS058 and 10C1B1I1 strains at $8 \mathrm{~h}$ culture (Table 2) compared to the WT strain, expressed as a red shift for Laurdan IF (Figure 3A). This effect was deepened at $24 \mathrm{~h}$ of culture, resulting in a red shift of Laurdan IFs (Figure 3B). An elevated level of ergosterol in the 10C1B1I1 strain resulted in a positive GP value, underlining the crucial role of ergosterol for PM properties.

The increased level of sterols such as lanosterol or eburicol corresponds to the decreased PM fluidity of KS058 when compared to the WT strain. FLC and AMB treatment also results in decreased GP values for all strains at $8 \mathrm{~h}$ and $24 \mathrm{~h}$ of culture, compared to control conditions. Interestingly, these antifungals also cause the increased fluidity of the KS058 strain PM, despite the absence of targets for these therapeutics (Erg11p and ergosterol, respectively). This could be a consequence of the increased lanosterol and eburicol content in the PM of the KS058 strain (Table 1). The rigidity of the PM in artificial bilayers can be affected by the structural motifs of sterols, and it generally increases with the elevated sterol content [8]. It has been proven that the treatment of S. cerevisiae with FLC corresponded to the reduction of PM rigidity, which led to a decreased order of lipids in the PM [34]. This suggests that the altered sterol composition of fungal PM after azole treatment impacts the lipid packaging, resulting in the decreased fluidity of the PM.

Our recent findings indicate deprivation of ergosterol from C. albicans' PM results in both chitin and $\beta$-glucan unmasking and the elevated expression of the genes involved in chitin (e.g., CHS3, CHS4) and $\beta$-glucan synthesis (e.g., GSC1, KRE9) [19]. Nevertheless, similar remodeling of the $\mathrm{CW}$ composition was never described for $C$. albicans strains carrying the single amino-acid substitution. In order to investigate whether the K143R mutation in Erg11p correlates with the altered CW structure, we applied quantitative analysis to all components of $C$. albicans $\mathrm{CW}$.

Microscopic study confirmed the alterations of the C. albicans KS058 and 10C1B1I1 CW compositions (Figure 4). After cytokinesis, the chitin layer is rebuilt in bud scars by specific enzymes [35], and so we observed a typical accumulation of chitin in this region of the cell. In the case of $C$. albicans $\mathrm{KS} 058(\operatorname{erg} 11 \Delta / \Delta)$, chitin is located near the mannans layer, in contrast to the $C$. albicans WT strain, where the chitin and mannans layers are separated (Figure 4). For C. albicans 10C1B1I1, chitin partially overlaps with the mannans signal (area of the bud scar). Furthermore, this study confirmed that in the C. albicans WT strain, exposed $\beta$-glucan is barely visible, indicating that it is normally hidden in the inner layers of the CW [16]. For both the KS058 and 10C1B1I1 strains, the unmasked $\beta$ glucan was present in the bud scar region. In contrast to the KS058 strain, for the 10C1B1I1 strain, exposed $\beta$-glucan was also present along the full fungal cell length. FACS analysis confirmed the partial exposure of chitin and $\beta$-glucan for the $C$. albicans ergosterol mutants (Figure 5). Additionally, a lower mannan content was detected for the C. albicans 10C1B1I1 
strain. This can be the consequence of the chitin and $\beta$-glucan layers shifting to the outer part of C. albicans CW (Figure 4).

So far, C. albicans $\mathrm{CW}$ remodeling has been described as a result of varying culture conditions (e.g., the addition of lactate to the culture medium) or a stress response to an antifungal drug treatment (e.g., caspofungin therapy) [14,36]. Here, we demonstrate that both the deprivation and the increased amount of ergosterol leads to the altered C. albicans CW composition. Furthermore, K143R substitution not only resulted in changes in the PM properties (decreased fluidity, elevated ergosterol content), but also in the CW composition. This demonstrates that one of the most common azole-resistance strategies (point mutation in ERG11 gene) has a pleiotropic effect on the cell morphology of C. albicans. It should be noted that rearrangement of $C$. albicans $C W$ could be crucial for the recognition of the pathogen by host PRRs. Thus, it is relevant to further investigate the impact of changes to the immune response that arose in C. albicans KS058 and 10C1B1I1 ergosterol mutants.

\section{Materials and Methods}

\subsection{Reagents and Chemicals}

The reagents and chemicals used in this study were obtained from the following sources: fluconazole, Laurdan, $\beta$-mercaptoethanol (BME), albumin fraction V (BSA), ethylenediaminetetraacetic acid (EDTA), phosphate buffered saline (PBS) tablets, CFW, WGA-FITC, ConA-FITC-conjugated, formaldehyde (Merck Life Science; Poznań, Poland); ConA (Vector Laboratories, Burlingame, USA); DNase I (Fermentas, distributor: Thermo Fisher, Waltham, MA, USA); High-Capacity cDNA Reverse Transcription Kit (manufacturer: Applied Biosystems, distributor: Thermo Fisher, Waltham, MA, USA); Total RNA Mini Kit (A\&A Biotechnology, Gdańsk, Poland); Alexa Fluor 568-conjugated streptavidin (Invitrogen, distributor: Thermo Fisher, Waltham, MA, USA); iTaq Universal SYBR Green Supermix (Bio-Rad, Hercules, CA, USA); conventional AMB, D-glucose, bacteriological agar, zymolyase, D-sorbitol, (manufacturer: BioShop; distributor: Epro Science, Puck, Poland); peptone, yeast extract (YE) (manufacturer: BD; distributor: Life Technologies; Warszawa, Poland); Fc-hDectin-1 (Invivogen, San Diego, CA, USA); Alexa Fluor 448conjugated anti-human IgG Fc antibodies (Thermo Fisher, Waltham, MA, USA); N,OBis(trimethylsilyl)trifluoroacetamide with trimethylchlorosilane (Merck, Darmstadt, Gemany); water (Merck); hydrochloric acid $(\mathrm{HCl})$, potassium hydroxide $(\mathrm{KOH})$, hexane (Merck); chloroform ( $\mathrm{CHCl} 3)$, methanol (MetOH) (Chempur; Piekary Ślaskie, Poland).

\subsection{Strains and Culture Conditions}

Strains used in this study were: C. albicans SC5314, which was kind gift from Prof. D. Sanglard (Lausanne, Switzerland) [37], and C. albicans 10C1B1I1, which was kind gift from Prof. D. Rogers (Department of Clinical Pharmacy, University of Tennessee Health Science Center, Memphis, TN, USA) (genotype: ERG11K143R::FRT/ERG11K143R::FRT, previously named C. albicans 10C1B1M1) [38]. C. albicans KS058 genotype is the same as SC5314, but called erg11 $::$ SAT1-FLIP/erg11 $:: F R T$ [22]. Strains were maintained in a YPD (yeast extract-peptone-dextrose) medium containing $1 \%$ yeast extract, $1 \%$ peptone, and $2 \%$ glucose. Two percent agar was used to solidify the medium. Strains were pre-cultured in the YPD medium, shaking $(120 \mathrm{rpm})$ at $28^{\circ} \mathrm{C}, 24 \mathrm{~h}$. For specific experiments, cells were grown in $20 \mathrm{~mL}$ YPD (starting $\mathrm{A}_{600}=0.1 ; 28^{\circ} \mathrm{C} ; 120 \mathrm{rpm}$; with or without the addition of FLC or AMB) for 8,14 or $24 \mathrm{~h}$, depending on the experiment.

\subsection{The Determination of Growth Phases (Growth Curve)}

In order to determine the growth phases, the $C$. albicans strains were pre-grown in the YPD medium $\left(28^{\circ} \mathrm{C}\right.$; with shaking: $\left.120 \mathrm{rpm}\right)$ overnight. Then $100 \mu \mathrm{L}$ of fresh YPD medium was added to the sterile 96-well plate (Sarstedt) and inoculated with C. albicans pre-culture to the final $\mathrm{A}_{600}=0.1$. The $\mathrm{A}_{600}$ was registered for $24 \mathrm{~h}$ at $1 \mathrm{~h}$ intervals using the Spark multimode microplate reader (Tecan, Männedorf, Switzerland). The experiment was independently replicated three times. 


\subsection{Minimal Inhibitory Concentration (MIC)}

For the purpose of the determination of the MIC values, a serial dilution of FLC or $\mathrm{AMB}$ was carried out at concentrations ranging from 0 to 256 or $16 \mu \mathrm{g} / \mathrm{mL}$, respectively. The YPD medium, supplemented with different concentrations of FLC or AMB, was inoculated with $C$. albicans overnight culture at a final $\mathrm{A}_{600}=0.01$ using sterile 96-well plates. The plates were then incubated for $24 \mathrm{~h}$ at $28^{\circ} \mathrm{C}$ and the optical density was measured using a plate reader at $\lambda=600 \mathrm{~nm}$ (Asys UVM 340, Biogenet, Cosenza, Italy). The negative and growth control groups were indicated by wells containing the YPD medium without tested compounds.

\subsection{Real-Time Quantitative PCR (RT-qPCR) Reaction}

C. albicans pellets were collected $\left(\mathrm{A}_{600}=20\right)$ and RNA isolated using a Total RNA Mini Kit according to the manufacturer's instructions. The concentration and purity of the isolated RNA was measured using a NanoDrop 2000 Spectrophotometer (Thermo Fisher Scientific, Waltham, MA, USA). In order to remove genomic DNA, samples were treated with DNAse I. The isolated RNA from all samples was brought to an equal concentration $(14 \mathrm{ng} / \mu \mathrm{L})$ and the cDNA was synthesized using a High-Capacity cDNA Reverse Transcription Kit.

The reaction was carried out using specific primers for genes $A C T 1$ (reference gene) and ERG11 as follows: ACT1F (5'-TCCAGCTTTCTACGTTTCCA-3'), ACT1R (5'-GTC AAGTCTCTACCAGCCAA-3'), ERG11F (5'-TTTGGTGGTGGTAGACATA-3'), ERG11R (5'-GAACTATAATCAGGGTCAGG-3'). RT-qPCR reaction was conducted using the iTaq Universal Sybr Green Supermix and the StepOnePlus Real-Time PCR System (Applied Biosystems, Waltham, MA, USA). The initial step of the thermal cycling program was performed at $95^{\circ} \mathrm{C}$ for $10 \mathrm{~min}$, followed by 40 cycles at $95^{\circ} \mathrm{C}$ for $20 \mathrm{~s}, 45^{\circ} \mathrm{C}$ for $20 \mathrm{~s}$, and $72{ }^{\circ} \mathrm{C}$ for $30 \mathrm{~s}$. The determination of gene expression levels was performed as described previously using the $2^{-\Delta \Delta \mathrm{Ct}}$ method [39].

\subsection{Plasma Membrane Isolation and Sterol Analyses}

The PM samples were isolated according to the previously reported method, with some modifications [40]. Briefly, cell sediment from C. albicans SC5314, 10C1B1I1, and KS058 after 8,14 and $24 \mathrm{~h}$ cultures $\left(\mathrm{A}_{600}=40\right)$ were resuspended in a lysis solution $(1 \mathrm{M}$ sorbitol, $0.1 \mathrm{M}$ EDTA, $1 \% \mathrm{BME}, 3 \mathrm{mg} / \mathrm{mL}$ zymolyase) and incubated for $30 \mathrm{~min}$ at $37^{\circ} \mathrm{C}$. Protoplasts were washed with $1.2 \mathrm{M}$ sorbitol, then ice-cold $\mathrm{H}_{2} \mathrm{O}_{\mathrm{dd}}$ was added and lysed using sonication (5-s cycles, 2 min each; $4^{\circ} \mathrm{C}$ ) using an ultrasonic processor (Heilscher $\mathrm{UP50H})$. The lysed cells were centrifuged $\left(10 \mathrm{k} \mathrm{rpm} ; 10 \mathrm{~min} ; 4^{\circ} \mathrm{C}\right)$ in order to remove the unbroken lysate. The supernatant was ultracentrifuged (100 k rpm; $\left.60 \mathrm{~min} ; 4^{\circ} \mathrm{C}\right)$ using a Micro Ultracentrifuge CS150FNX (Hitachi; Tokyo, Japan). The crude PM pellets were resuspended in phosphate-buffered saline (PBS) with $\mathrm{CHCl}_{3}-\mathrm{MetOH}(1: 2 v / v)$. The $\mathrm{CHCl}_{3}$ phase was transferred to glass vials and concentrated using nitrogen gas after continuous stirring at $4{ }^{\circ} \mathrm{C}$ for $48 \mathrm{~h}$.

\subsection{GC-MS Sterol Analysis in the Plasma Membrane}

The work-up procedure was previously described [22]. We added to the concentrated lipid extracts $0.5 \mathrm{~mL} \mathrm{CHCl}, 0.5 \mathrm{~mL}$ MetOH-KOH $(0.6 \mathrm{M})$, and $20 \mu \mathrm{L}$ cholesterol solution in $\mathrm{CHCl}_{3}$ (calibration standard, $1 \mathrm{mg} / \mathrm{mL}$ ). The samples were vortexed and incubated at $23{ }^{\circ} \mathrm{C}$ for $1 \mathrm{~h}$. Then, $0.325 \mathrm{~mL} 1 \mathrm{M} \mathrm{HCl}$ and $0.125 \mathrm{~mL} \mathrm{H}_{2} \mathrm{O}$ were added and centrifuged ( $5000 \mathrm{rcf} ; 10^{\circ} \mathrm{C} ; 5 \mathrm{~min}$ ). The lower chloroform layer containing the lipids was transferred to $1.5 \mathrm{~mL}$ Eppendorf tubes and dried. Then, $100 \mu \mathrm{L}$ of silylation reagent BSTFA + TMCS was added and heated for complete silylation at $85{ }^{\circ} \mathrm{C}$ for $90 \mathrm{~min}$. The cooled samples were supplemented with $50 \mu \mathrm{L}$ of hexane and vortexed. An analysis was performed using a gas chromatograph (Agilent 7890) equipped with HP-5ms columns (30 m $\times 0.25 \mathrm{~mm}$ inner diameter, i.d. $\times 0.25 \mathrm{~mm}$ film thickness, f.t.) and a 5975C Mass Detector. The column was maintained at $100{ }^{\circ} \mathrm{C}$ for $0.5 \mathrm{~min}^{-1}$, then increased to $240{ }^{\circ} \mathrm{C}$ at a rate of $25^{\circ} \mathrm{C} \mathrm{min}-1$, and 
finally to $300{ }^{\circ} \mathrm{C}$ at a rate of $3{ }^{\circ} \mathrm{C} \mathrm{min}^{-1}$ (for $5 \mathrm{~min}$ ) with helium as a carrier gas at a flow rate of $1 \mathrm{~mL} \cdot \mathrm{min}^{-1}$ [22]. The injection port temperature was $250{ }^{\circ} \mathrm{C}$. The sterols were analyzed as trimethylsilyl (TMS) ethers. The ergosterol and lanosterol were analyzed with reference to retention times and fragmentation spectra for standards. Other sterol TMS ethers were identified by comparison with the NIST database, or literature data, and quantitated using a standard curve for lanosterol.

\subsection{The Plasma Membrane Fluidity Measurement (Laurdan Fluorescent Probe)}

The PM fluidity was determined using a previously described method [22]. Laurdan is a fluorescent probe which is commonly used for determining the lipid packing in the PM [41]. Briefly, samples of the C. albicans WT, KS058, and 10C1B1I1 strains collected after $8 \mathrm{~h}$ and $24 \mathrm{~h}$ of culture were harvested and adjusted to $\mathrm{A}_{600}=0.1$ in $3 \mathrm{~mL}$ of PBS. The suspensions were incubated with a Laurdan fluorescent probe at a final concentration of $5 \times 10^{-6} \mathrm{M}$ for $20 \mathrm{~min}$ at RT in darkness. Laurdan probes were excited at $\lambda=366 \mathrm{~nm}$ $($ ex slit $=10 \mathrm{~nm})$ and fluorescence spectra were recorded at 400-550 nm $($ em slit $=2.5 \mathrm{~nm})$ using a fluorescence spectrophotometer equipped with a xenon lamp (HITACHI F-4500; manufacturer: Hitachi, Tokyo, Japan). The general polarization (GP) of the Laurdan probe incorporated in the PM of investigated strains was calculated using following formula:

$$
\mathrm{GP}=\frac{\sum_{425 \mathrm{~nm}}^{450 \mathrm{~nm}} I F-\sum_{475 \mathrm{~nm}}^{525 \mathrm{~nm}} I F}{\sum_{425 \mathrm{~nm}}^{450 \mathrm{~nm}} I F+\sum_{475 \mathrm{~nm}}^{525 \mathrm{~nm}} I F}
$$

where: $I F=$ fluorescence intensities determined for the Laurdan fluorescent probe at a certain range of wavelength.

\subsection{Staining of Cell Wall and Structured Illumination Microscopy (SIM)}

In order to determine the CW components, triple staining of C. albicans cells was performed. The mannans were stained using ConA dissolved in PBS containing 3\% BSA, $1 \mathrm{mM} \mathrm{Ca}^{2+}$, and $\mathrm{Mn}^{2+}$ and streptavidin conjugated with Alexa Fluor-568. Total chitin was visualized using CFW. The unmasked $\beta$-glucans were stained according to the protocol of Wagener et al. [42]. The C. albicans $24 \mathrm{~h}$ cultures were centrifuged and washed twice with PBS $(4000 \times g, 5 \mathrm{~min})$ and adjusted to A600 $=1$ in PBS with 3\% BSA. First, cells were incubated using $5 \mu \mathrm{g} / \mathrm{mL}$ of ConA for $1 \mathrm{~h}, 37^{\circ} \mathrm{C}$. The cells were washed twice with PBS and treated with 1:200 Alexa Fluor 568 conjugated streptavidin for $1 \mathrm{~h}, 37^{\circ} \mathrm{C}$. The cells were washed twice with PBS and $5 \mu \mathrm{g} / \mathrm{mL}$ Fc-hDectin- 1 was added. After $1 \mathrm{~h}$ incubation, the cells were washed twice $(4000 \times g, 5 \mathrm{~min})$ and resuspended in PBS. The Fc-hDectin-1 treated cells were incubated with 1:250 Alexa Fluor 448-conjugated anti-human IgG Fc antibodies for $1 \mathrm{~h}, 4^{\circ} \mathrm{C}$. After that, the cells were washed twice as above, resuspended in PBS, and stained with CFW $(0.025 \mathrm{mM})$ for $5 \mathrm{~min}$, RT [43]. The cells were washed twice as above, resuspended in PBS, and concentrated. The observation of the preparations (at least 50 cells for each investigated strain) was performed using a super-resolution microscope (ZEISS Elyra 7 with Lattice SIM; Oberkochen, Germany).

\subsection{Fluorescence-Activated Cell Sorting (FACS) Analyses}

The $C$. albicans cell wall components were visualized as follows: the exposed $\beta$-glucan was stained with Fc-hDectin-1 (Section 4.9); the mannans were stained with $50 \mu \mathrm{g} / \mathrm{mL}$ ConA conjugated with FITC for $5 \mathrm{~min}$, RT. The unmasked chitin was stained with WGAFITC for $1 \mathrm{~h}$, on ice [19]. After each staining, the cells were washed twice with PBS and in all cases, fixed with 3.7\% formaldehyde for $15 \mathrm{~min}$. After that, the cells were pelleted, washed twice with PBS, and resuspended in PBS. In order to perform the FACS analyses, the cell suspensions were diluted from 1:2 to 1:10, and 20,000 events were collected using a NovoCyte 2060R flow cytometer. Data were analyzed using NovoExpress software (ACEA Biosciences, San Diego, CA, USA). The fluorescent signal was obtained at a wavelength of $488 \mathrm{~nm}$. 


\subsection{Statistical Analyses}

For data analysis, statistical significance was determined using a Student's t-test (binomial, unpaired). Data represent the means \pm standard errors from at least three biological replicates.

Author Contributions: Conceptualization, A.K.; methodology and investigation, D.D. and P.B.; writing-original draft preparation, D.D. and A.K.; writing - review and editing, funding, and supervision, A.K. All authors have read and agreed to the published version of the manuscript.

Funding: Publication of this article in open access was financially supported by the Excellence Initiative-Research University (IDUB) program for the University of Wrocław.

Acknowledgments: The authors would like to thank and acknowledge Michał Majkowski (Faculty of Biotechnology, University of Wrocław) for his technical support of the super-resolution microscopy analysis.

Conflicts of Interest: The authors declare no conflict of interest.

\section{References}

1. Gao, Y.; Liang, G.; Wang, Q.; She, X.; Shi, D.; Shen, Y.; Su, X.; Wang, X.; Wang, W.; Li, D.; et al. Different Host Immunological Response to C. albicans by Human Oral and Vaginal Epithelial Cells. Mycopathologia 2019, 184, 1-12. [CrossRef] [PubMed]

2. Yeşilbağ, Z.; Şeker, Y.T.; Avci, K.D.; Şenoğlu, S.; Çukurova, Z.; Hergünsel, G.O. Changing epidemiology and risk factors for candidemia in critically ill patients. J. Surg. Med. 2021, 5, 97-102. [CrossRef]

3. Tsay, S.V.; Mu, Y.; Williams, S.; Epson, E.; Nadle, J.; Bamberg, W.M.; Barter, D.M.; Johnston, H.L.; Farley, M.M.; Harb, S.; et al. Burden of Candidemia in the United States, 2017. Clin. Infect. Dis. 2020, 71, 449-453. [CrossRef] [PubMed]

4. Patterson, L.; McMullan, R.; Harrison, D.A. Individual risk factors and critical care unit effects on Invasive Candida Infec-tion occurring in critical care units in the UK: A multilevel model. Mycoses 2019, 62, 790-795. [PubMed]

5. Bhattacharya, S.; Sae-Tia, S.; Fries, B.C. Candidiasis and Mechanisms of Antifungal Resistance. Antibiotics 2020, 9, 312. [CrossRef] [PubMed]

6. Maertens, J. History of the development of azole derivatives. Clin. Microbiol. Infect. 2004, 10, 1-10. [CrossRef] [PubMed]

7. Whaley, S.G.; Berkow, E.L.; Rybak, J.M.; Nishimoto, A.T.; Barker, K.S.; Rogers, P.D. Azole Antifungal Resistance in Candida albicans and Emerging Non-albicans Candida Species. Front. Microbiol. 2017, 7, 2173. [CrossRef]

8. Fumiyoshi, A.; Toshiki, H. Mechanistic role of ergosterol in membrane rigidity and cycloheximide resistance in Saccharomyces cerevisiae. Biochim. Biophys. Acta (BBA)-Biomembr. 2009, 1788, 743-752.

9. Francois, E.J.A.I.; Cammue, B.P.A.; Borgers, M.; Ausma, J.; Dispersyn, G.D.; Thevissen, K. Azoles: Mode of Antifungal Action and Resistance Development. Effect of Miconazole on Endogenous Reactive Oxygen Species Production in Candida albicans. Anti-Infect. Agents Med. Chem. 2006, 5, 3-13. [CrossRef]

10. Pristov, K.E.; Ghannoum, M.A. Resistance of Candida to azoles and echinocandins worldwide. Clin. Microbiol. Infect. 2019, 25, 792-798. [CrossRef]

11. Banerjee, A.; Pata, J.; Sharma, S.; Monk, B.C.; Falson, P.; Prasad, R. Directed Mutational Strategies Reveal Drug Binding and Transport by the MDR Transporters of Candida albicans. J. Fungi 2021, 7, 68. [CrossRef] [PubMed]

12. Vandeputte, P.; Ferrari, S.; Coste, A.T. Antifungal Resistance and New Strategies to Control Fungal Infections. Int. J. Microbiol. 2012, 2012, 713687. [CrossRef] [PubMed]

13. Bossche, H.V.; Marichal, P.; Odds, F.C. Molecular mechanisms of drug resistance in fungi. Trends Microbiol. 1994, 2, 393-400. [CrossRef]

14. Letscher-Bru, V.; Herbrecht, R. Caspofungin: The first representative of a new antifungal class. J. Antimicrob. Chemother. 2003, 51, 513-521. [CrossRef] [PubMed]

15. Lin, J.; Wester, M.J.; Graus, M.S.; Lidke, K.A.; Neumann, A.K. Nanoscopic cell-wall architecture of an immunogenic ligand in Candida albicans during antifungal drug treatment. Mol. Biol. Cell 2016, 27, 1002-1014. [CrossRef] [PubMed]

16. Garcia-Rubio, R.; De Oliveira, H.C.; Rivera, J.; Trevijano-Contador, N. The Fungal Cell Wall: Candida, Cryptococcus, and Aspergillus Species. Front. Microbiol. 2020, 10, 2993. [CrossRef] [PubMed]

17. Gow, N.A.; Hube, B. Importance of the Candida albicans cell wall during commensalism and infection. Curr. Opin. Microbiol. 2012, 15, 406-412. [CrossRef]

18. Shibata, N.; Suzuki, A.; Kobayashi, H.; Okawa, Y. Chemical structure of the cell-wall mannan of Candida albicans serotype A and its difference in yeast and hyphal forms. Biochem. J. 2007, 404, 365-372. [CrossRef]

19. Suchodolski, J.; Derkacz, D.; Muraszko, J.; Panek, J.J.; Jezierska, A.; Łukaszewicz, M.; Krasowska, A. Fluconazole and Lipopeptide Surfactin Interplay During Candida albicans Plasma Membrane and Cell Wall Remodeling Increases Fungal Immune System Exposure. Pharmaceutics 2020, 12, 314. [CrossRef]

20. Manastır, L.; Ergon, M.C.; Yucesoy, M. Investigation of mutations in Erg11 gene of fluconazole resistant Candida albicans isolates from Turkish hospitals. Mycoses 2011, 54, 99-104. [CrossRef] 
21. Healey, K.R.; Kordalewska, M.; Jiménez Ortigosa, C.; Singh, A.; Berrío, I.; Chowdhary, A.; Perlin, D.S. Limited ERG11 Mu-tations Identified in Isolates of Candida auris Directly Contribute to Reduced Azole Susceptibility. Antimicrob. Agents Chemother. 2018, 62, e01427-18. [CrossRef] [PubMed]

22. Suchodolski, J.; Muraszko, J.; Bernat, P.; Krasowska, A. A Crucial Role for Ergosterol in Plasma Membrane Composition, Localisation, and Activity of Cdr1p and $\mathrm{H}^{+}$-ATPase in Candida albicans. Microorganisms 2019, 7, 378. [CrossRef] [PubMed]

23. Pappas, P.G.; Lionakis, M.S.; Arendrup, M.C.; Ostrosky-Zeichner, L.; Kullberg, B.J. Invasive candidiasis. Nat. Rev. Dis. Primers 2018, 4, 18026. [CrossRef] [PubMed]

24. Pradhan, A.; Avelar, G.M.; Bain, J.M.; Childers, D.; Pelletier, C.; Larcombe, D.E.; Shekhova, E.; Netea, M.G.; Brown, G.D.; Erwig, L.; et al. Non-canonical signalling mediates changes in fungal cell wall PAMPs that drive im-mune evasion. FEMS Yeast Res. 2019, $10,5315$.

25. Xiang, M.J.; Liu, J.Y.; Ni, P.H.; Wang, S.; Shi, C.; Wei, B.; Ni, Y.X.; Ge, H.L. Erg11 mutations associated with azole re-sistance in clinical isolates of Candida albicans. FEMS Yeast Res. 2013, 13, 386-393. [CrossRef] [PubMed]

26. Hargrove, T.Y.; Friggeri, L.; Wawrzak, Z.; Qi, A.; Hoekstra, W.J.; Schotzinger, R.J.; York, J.D.; Guengerich, F.P.; Lepesheva, G.I. Structural analyses of Candida albicans sterol $14 \alpha$-demethylase complexed with azole drugs address the molecular basis of azole-mediated inhibition of fungal sterol biosynthesis. J. Biol. Chem. 2017, 292, 6728-6743. [CrossRef]

27. Flowers, S.A.; Barker, K.S.; Berkow, E.L.; Toner, G.; Chadwick, S.G.; Gygax, S.E.; Morschhäuser, J.; Rogers, P.D. Gain-of-function mutations in UPC2 are a frequent cause of ERG11 upregulation in azole-resistant clinical isolates of Candida albicans. Eukaryot. Cell 2012, 11, 1289-1299. [CrossRef]

28. Oliver, B.G.; Song, J.L.; Choiniere, J.H.; White, T.C. Cis-Acting elements within the Candida albicans ERG11 promoter me-diate the azole response through transcription factor Upc2p. Eukaryot. Cell 2007, 6, 2231-2239. [CrossRef]

29. Du, J.; Ma, W.; Fan, J.; Liu, X.; Wang, Y.; Zhou, X. The A756T Mutation of the ERG11 Gene Associated With Resistance to Itraconazole in Candida Krusei Isolated From Mycotic Mastitis of Cows. Front. Vet. Sci. 2021, 8, 634286. [CrossRef]

30. Vu, B.G.; Moye-Rowley, W.S. Multiple mechanisms impact fluconazole resistance of mutant Erg11 proteins in Candida glabrata. bioRxiv 2021, 449691. [CrossRef]

31. Gale, E.F. The Release of Potassium Ions from Candida albicans in the Presence of Polyene Antibiotics. Microbiology 1974, 80, 451-465. [CrossRef] [PubMed]

32. Zhu, C.; Liao, B.; Ye, X.; Zhou, Y.; Chen, X.; Liao, M.; Cheng, L.; Zhou, X.; Ren, B. Artemisinin elevates ergosterol levels of Candida albicans to synergise with amphotericin B against oral candidiasis. Int. J. Antimicrob. Agents 2021, 58, 106394. [CrossRef]

33. Sanglard, D.; Ischer, F.; Parkinson, T.; Falconer, D.; Bille, J. Candida albicans mutations in the ergosterol biosynthetic path-way and resistance to several antifungal agents. Antimicrob. Agents Chemother. 2003, 47, 2404-2412. [CrossRef]

34. Abe, F.; Usui, K.; Hiraki, T. Fluconazole modulates membrane rigidity, heterogeneity, and water penetration into the plasma membrane in Saccharomyces cerevisiae. Biochemistry 2009, 48, 8494-8504. [CrossRef] [PubMed]

35. Lenardon, M.D.; Munro, C.; Gow, N.A. Chitin synthesis and fungal pathogenesis. Curr. Opin. Microbiol. 2010, 13, 416-423. [CrossRef] [PubMed]

36. Ballou, E.R.; Avelar, G.M.; Childers, D.S.; Mackie, J.; Bain, J.M.; Wagener, J.; Kastora, S.L.; Panea, M.D.; Hardison, S.E.; Walker L.A.; et al. Lactate signalling regulates fungal $\beta$-glucan masking and immune evasion. Nat. Microbiol. 2016, 12, 16238. [CrossRef]

37. Fonzi, W.A.; Irwin, M.Y. Isogenic strain construction and gene mapping in Candida albicans. Genetics 1993, 134, 717-728. [CrossRef]

38. Flowers, S.A.; Colón, B.; Whaley, S.G.; Schuler, M.A.; Rogers, P.D. Contribution of Clinically Derived Mutations inERG11to Azole Resistance in Candida albicans. Antimicrob. Agents Chemother. 2014, 59, 450-460. [CrossRef]

39. Szczepaniak, J.; Łukaszewicz, M.; Krasowska, A. Estimation of Candida albicans ABC Transporter Behavior in Real-Time via Fluorescence. Front. Microbiol. 2015, 6, 1382. [CrossRef]

40. Suchodolski, J.; Muraszko, J.; Korba, A.; Bernat, P.; Krasowska, A. Lipid composition and cell surface hydrophobicity of Candida albicans influence the efficacy of fluconazole-gentamicin treatment. Yeast 2020, 37, 117-129. [CrossRef]

41. Amaro, M.; Reina, F.; Hof, M.; Eggeling, C.; Sezgin, E. Laurdan and Di-4-ANEPPDHQ probe different properties of the membrane. J. Phys. D Appl. Phys. 2017, 50, 134004. [CrossRef] [PubMed]

42. Wagener, J.; MacCallum, D.M.; Brown, G.D.; Gow, N.A. Candida albicans chitin in-creases arginase-1 activity in human macrophages, with an impact on macrophage antimicrobial functions. MBio 2017, 8, e01820-16. [CrossRef] [PubMed]

43. Suchodolski, J.; Feder-Kubis, J.; Krasowska, A. Antifungal activity of ionic liquids based on (-)-menthol: A mechanism study. Microbiol. Res. 2017, 197, 56-64. [CrossRef] [PubMed] 